\title{
Kon!k RUANG SEBAGAI SUMBER IDE PENCIPTAAN SENI LUKIS KESENJANGAN WILAYAH
}

Volume 2, Nomor 2 Juli 2020, (87-94)

\section{Sehpenganti}

Penciptaan Seni / Seni kriya Tekstil

Pascasarjana Institut Seni Indonesia Yogyakarta

e-mail : pengantiseh@gmail.com

\begin{abstract}
ABSTRAK
Penciptaan karya seni kriya ini merepresentasikan tentang fenomena kerusakan alam yang mengakibatkan hampir punahnya habitat bunga rafflesia arnoldi . Buna rafflesia arnoldi sebagai inspirasi penciptaan karya seni serat memiliki beberapa keunikan dan kelebihan, Ide dasar penciptaan berangkat dari pesona visual yang indah, Bunga rafflesia arnoldii sebagai tumbuhan endemik dipulau sumatra khusunya di kota Bengkulu. Bunga rafflesia arnoldii dikenal tidak memiliki daun sehingga tidak mampu melakukan fotosintesis sendiri, maka untuk memenuhi kebutuan hidupnya mengambil nutrisi dari pohon inangnya. Keunikan bunga Rafflesia arnoldii memiliki sifat-sifat biologi yang berbeda dengan tumbuhan lainnya yaitu memiliki daur hidup tahunan dan memparasiti spesies liana tertentu. Diduga bahwa permasalahan lingkungan akan menjadi penyebab utama kepunahan Rafflesia arnoldii. Selain hal itu terjadinya kepunahan disebabkan oleh proses pertumbuhan kuncup-kuncup bunga yang akan mekar dalam waktu yang singkat. Masa pertumbuhan bunga dapat memakan waktu sampai 9 bulan dan masa mekar hanya sekitar 5-7 hari, kemudian bunga Rafflesia arnoldi akan layu dan mati. Penciptaan karya ini menerapkan metode tiga-tahap enam-langkah dari SP. Gustami. Karya yang diciptakan adalah karya seni kriya tekstil dalam bentuk karya seni serat. Proses pembuatan karya terdiri dari proses pembuatan desain, pembentukan, finishing, dan evaluasi. Proses penghayatan, penyetaraan antara rasa dan pikiran, dilakukan untuk memberikan spirit dan ruh agar karya dapat memberikan inspirasi, semangat, dan memberikan pesan-pesan kepada orang lain yang melihatnya. Material utama karya yang digunakan yaitu berbagai jenis benang serat alami dan serat buatan, kain goni sedangkan material pendukung yaitu serat alam, payet dan berbagai jenis aksesoris. Penelitian dan penciptaan ini menghasilkan dua karya yang tediri dari karya panel dua dimensi. Setiap karya menceritakan makna yang berbeda tetapi tetap ada korelasi konsep yang sama. Harapannya karya-karya penciptaan ini bisa memberikan sebuah refleksi dari berbagai sudut pandang latar belakang kehidupan manusia.
\end{abstract}

Kata Kunci: Kota Bengkulu, Bunga rafflesia arnoldi, seni serat

\section{ABSTRACT}

The creation of this craft art is to represent the natural destruction phenomenon which causes the extinction of Rafflesia Arnoldi flowers habitat. Rafflesia Arnoldi flowers as an inspiration of fiber artwork creation which have several uniqueness and advantages, the basic idea of creation is started from the beautiful visual charm, Rafflesia Arnoldi flowers as endemic plants in the Sumatra Island especially in Bengkulu City. Rafflesia Arnoldi flowers are known as the plants which have no leaves, therefore they are unable to carry out photosynthesis by themselves; consequently to fullfill their life's needs, they take nutrients from their host trees. The uniqueness of Rafflesia Arnoldi flowers have different biological characteristics with the other plants which have annual life cycles and paralyze the certain Liana' species. It is suspected that the enviromental problem will be as the main cause of Raffesia Arnoldi' extinction. In other hand, the extinction is also caused by the growth process of flower buds that will bloom in a short time. the growth period can take up into 9 months and the bloom period is only about 5-7 days, then the Rafflesia Arnoldi flowers will wither and die. The creation of this work applies the six-steps three-stages method of SP. Gustami. The work, which is created, is a textile artwork in the fiber artwork form. The process of making works consist of making design process, forming, finishing, and evaluating. In the appreciation process, the equalization between feeling and mind. It is carried out to give passion and spirit so the work can give an inspiration, encouragement, and give the messages to others who perceives it. The main material used is various types of natural fiber yarns and synthetic fibers, sackcloth while supporting materials are natural fibers, sequins and various types of accessories. This research and creation result two works, which consist of two dimensional panel works. Each work tells the different meaning but there is the same of correlation' concept. Hopefully, this creation' works are able to provide a reflection of various viewpoints in the human life.

Kata Kunci: Bengkulu City, Rafflesia Arnoldi Flower, Fiber art 


\section{PENDAHULUAN}

Tumbuhan dari sub-famili Rafflesiaceae dalam ilmu hayati merupakan tumbuhan holoparasites atau jenis tumbuhan 'parasit akar' yang dikenal dengan nama fotosintesis yaitu tumbuhan yang tidak dapat melakukan produksi makanan sendiri. Sebagaimana dalam (Lambers et al, 1998) holoparasites merupakan parasit (obligat) yang pemenuhan kebutuhan hidupnya bergantung sepenuhnya pada inang atau tumbuhan yang tempeli (di-rambati).

Bunga Rafflesia arnoldii atau dikenal dengan nama padma raksasa atau bunga raksasa merupakan tumbuhan parasit obligat. Tidak semua pohon inang akan dapat menjdi rumah untuk bunga Rafflesia arnoldii. Keunikan bunga tersebut tidak lepas dari sejarah penemuanya yang pertama kali ditemukan pada tahun (1818) di hutan tropis Sumatera, oleh seorang pemandu yang bekerja pada Dr. Joseph Arnold yang sedang mengikuti ekspedisi Thomas Stanford Raffles. Nama tumbuhan itu terinspirasi nama penemunya yakni penggabungan antara Raffles dan Arnoldii.

Bunga rafflesia arnoldi sebagai tumbuhan endemik di pulau Sumatra khusunya di provinsi kota Bengkulu. Bunga rafflesia arnoldi dikenal tidak memiliki daun sehingga tidak mampu melakukan fotosintesis sendiri, maka untuk memenuhi kebutuan hidupnya mengambil nutrisi dari pohon inangnya. Keunikan bunga Rafflesia arnoldii memiliki sifat-sifat biologi yang berbeda dengan tumbuhan lainnya yaitu memiliki daur hidup tahunan dan memparasiti spesies liana tertentu Diduga bahwa permasalahan lingkungan akan menjadi penyebab utama kepunahan Rafflesia arnoldi. Selain hal itu terjadinya kepunahan disebabkan oleh proses pertumbuhan kuncupkuncup bunga yang akan mekar dalam waktu singkat. Masa pertumbuhan bunga dapat memakan waktu sampai 9 bulan dan masa mekar hanya sekitar 5-7 hari, kemudian bunga Rafflesia arnoldi akan layu dan mati.

Pada saat ini penulis mendapatkan data bahwa bunga Rafflesia arnoldi ini oleh kelompok PELISWISTA (Pemuda Peduli Wisata) secara langsung dilakukan konservasi. upaya konservasi habitat yang dilakukan oleh sekelompok pemuda PELISWISTA di daerah Bengkulu Utara daerah Kaur bekerjasama dengan berbagai mitra terkait. Pengembangan pada beberapa titik dengan membangun kesadaran dan kepedulian masyarakat untuk menjaga dan melestarikan tumbuhan khas Indonesia tersebut.

Visual keindahan wujud bunga Rafflesia arnoldi yang mendorong penulis untuk mengangkat Rafflesia arnoldi sebagai objek dalam karya ini, Selain itu keunikan wujud bunga Rafflesia arnoldi dan pola bertahan hidup yang sangat singkat, penulis ingin menyimbolkan bunga Rafflesia arnoldi sebagai simbol peroses kehidupan peribadi penulis. Peroses pertumbuhan bunga Rafflesia arnoldi memakan waktu cukup lama dan masa hidup yang singkat, sama halnya dengan perjalanan hidup penulis yang tidak tau kapan dan berapa lama dalam proses menjalani kehidupan yang pada ahirnya akan kembali kepada yang kuasa. natinya akan diciptakan kedalam karya dua dimensi, dengan ide bunga Rafflesia arnoldi sebagai sumper penciptaanya.

Melalui proses interpretasi penulis mengapresiasikan bunga Rafflesia arnoldi dalam karya yang menitik beratkan kepada teknik dalam tekstil yang disebut dengan teknik tapestry, ada beberapa teknik pengerjaan tekstil non tenun yang penulis gunakan sebagai variasi seperti kolase dan makrame. Selain serat alam maupun serat sintetis yang digunakan untuk material utamanya, penulis mengunakan bahan kain goni, kanvas, kain asahi sebagai ekspresi seperti ini disebut sebagai karya seni serat (fiber art) yang digunakan sebagai objek penekanan material secara konseptual (Anas, 2006: 51).

Karya seni serat dianggap mewarisi sikap dan pandangan craft yang menganggap penting aspek ketrampilan kerja (crafting) dalam proses penciptaan karya seni. Karya dengan tema bunga Rafflesia arnoldi yang dikerjakan menggunakan teknik sulam jahit isi dan makrame. Penulis mencoba memahami tekstil dan benang yang dikhususkan sebagai objek apresiasi seni. Pemahaman semacam ini, menciptakan kategori tertentu yang memposisikan material tekstil dan benang sebagai media ekspresi diri.

Susunan seni tidak hanya menetapkan cara seseorang menikmati dan memahami karya seni (proses apresiasi), namun juga merumuskan syarat hingga pada jenjang bentuk-bentuk ekspresi seni. Pembahasan tentang tekstil dan benang memang bukan hanya soal jenis bahan atau teknik dalam pembuatan, tetapi juga termasuk fungsi dan perannya. Ekspresi seni melalui medium tekstil atau serat menunjukkan kaitan nilai-nilai yang diakui oleh masyarakat, bahkan mengikat identitas kultural secara tertentu yang bersifat personal maupun sosial. Jika kita menyebut istilah tekstil atau kain, kita pasti berfikir benda dan atribut pengalaman keseharian seperti pakaian maupun alat rumah tangga. Meski demikian, pilihan seseorang atau kelompok masyarakat tertentu pada jenis tekstil juga bisa terkait adat dan kebiasaan budaya yang menyangkut identitas suatu kebudayaan.

Karya yang penulis ciptakan dapat dikategorikan dalam karya seni serat (fiber art), yaitu ekspresi seni yang menggunakan material 
serat (alami ataupun sintetis) sebagai pokok dasar mediumnya. Proses perwujudan juga tidak mudah dan bisa langsung menemukan kesetarataan kondisi apresiasi perkembangan karya serat yang semacam ini justru menunjukkan proses dialog yang intens serta menarik khususnya dalam wacana Seni Kriya. Mengingat peta Seni Kriya Indonesia yang hingga saat ini belum banyak disinggung dan mendapat sorotan lebih jauh, maka karya-karya semacam ini, tidak hanya mengantar kita pada keberagaman perkembangan praktek Seni Kriya Indonesia, namun secara khusus juga akan menunjukkan sisi lain perkembangan seni rupa abstrak selain dalam ekspresi diluar seni lukis.

\section{METODE PENCIPTAAN}

\section{Teknik Pendektan}

\section{Pendekatan Estetik}

Penciptaan ini mengacu pada wujud karya kriya seni yang meletakkan fungsi estetis dan sosial sebagai fungsi utama. Teori-teori pendukung dalam proses penciptaan karya ini berkaitan dengan metode, teori estetika, teori tanda. Setiap teori memiliki karakter dan fungsi sendiri-sendiri tetapi masih memiliki keterkaitan antara satu dengan lainnya, yang nantinya akan diterapkan dalam karya seni.

Bungga Rafflesia Arnoldi merupakan simbol Kota Bengkulu. Penciptaan bungga Rafflesia Arnoldi pada karya seni serat ini melalui proses yang cukup panjang. Perpaduan bentuk, warna, dan unsur seni rupa lainnya menunjukkan sebuah susunan yang bernilai estetis. Seperti yang diungkapkan Dharsono Sony Kartika bahwa "indah pada dasarnya terdiri dari kualitas pokok yang meliputi kesatuan, keselarasan, kesetangkupan, keseimbangan, dan perlawanan" (Darsono Sony Kartika, 2004: 11)

Teori tanda atau semiotika yang digunakan dalam penciptaan ini adalah teori dari Peirce. Peirce menjelaskan tentang hubungan-hubungan tanda yang sering dikenal dengan trikotomi Peirce. Teori ini memuat hubungan tanda dengan tanda, tanda dengan objek, dan tanda dengan penafsir (Arthur Asa berger, 2010: 33). Trikotomi Peirce berisikan tentang hubungan tiga unsur yang saling melengkapi yaitu "objek, representamen, dan interpretan" (Kris Budiman, 2011: 17)

\section{Pendekatan Fenomenannologi}

Pendekatan Fenomenanologi Kuswarno 2009 dalam (Sani, 2015:4), menyebutkan bahwa fenomenologi merupakan pendekatan yang dengan sudut pandang subjektivisme, yaitu melihat sesuatu bukan hanya dari suatu gejala, namun juga berusaha untuk menggali makna yang terdapat pada gejala tersebut. kesadaran merupakan cara berfikir yang mengarah pada suatu hal berdasarkan keinginan dan merupakan kesimpulan dari sebuah kesadaran.

Cara pandang fenomenologi semacam ini dianggap tepat oleh penulis dalam penciptaan karyanya. Fenomenologi menjelaskan mengenai persepsi atau sudut pandang, fenomenologi juga menjelaskan bagaimana seseorang berfikir dan menyadari keberadaan benda tersebut. Seperti apa yang disampaikan penulis pada penciptaan karyanya, Teori fenomenologi membantu menjelaskan mengenai sudut pandang penulis pada kerusakan alam yang menggakibatkan hampir punahnya bunga padma raksasa dalam Penciptaan "Karya Seni Serat Sebagai Media Espresi Diri" subjektivitas seorang seniman dalam memandang suatu benda maupun suatu kejadian melalui sudut pandangnya untuk kemudian dituangkan ke dalam karya seni sesuai apa yang ingin disampaikan

\section{Teknik Penciptaan}

Dalam penciptaan ini metode yang digunakan adalah metode penciptaan karya seni menurut Sp. Guatami "Teori penciptaan Gustami terdiri dari tiga tahap-enam langkah penciptaan seni kriya. Pertama tahap eksplorasi yang meliputi pengamatan, dan pencarian sumber pustaka. Kedua, tahap perancangan yaitu membuat beberapa sketsa, dan pembuatan gambar teknik. Tahap ketiga, perwujudan yaitu proses pembentukan, dan dilanjutkan penilaian dan evaluasi karya yang telah jadi" (Gustami, 2004: 29-32).

\section{Tahap Eksplorasi}

Ide utama penciptaan ini yaitu tentang eksplorasi bentuk bunga Rafflesia arnoldi dalam karya kriya tekstil. Pada penciptaan ini akan difokuskan pada pengunaan matrial dan struktur bunga yang dibongkar dari bentuk asli bunga Rafflesia Arnoldi yang dijadikan simbol pribadi penulis. ditinjau dari sistemnya, karya yang diciptakan bisa bergerak dinamis.

a. Pengamatan dilakukan untuk mengamati bentuk-bentuk bunga Rafflesia Arnoldi . Hal ini dimaksudkan untuk mencari macam-macam bentuk, sehingga dapat ditemukan bentuk baru yang lain daripada yang lain.

b. Studi pustaka dan kajian tentang Rafflesia Arnoldi dan seni serat. Berkaitan dengan teoriteori yang dipakai, menggunakan buku-buku yang berkaitan dengan estetika terutama tentang bentuk, desain, dan semiotik. Data observasi langsung dengan bunga Rafflesia Arnoldi yang berada di Desa Ulak bandung, Kecamatan Muara Sarung, Kabupatan Kaur, Bengkulu Utara.

\section{Perancangan}


Pembuatan sketsa dan desain, dimaksudkan agar bentuk yang diinginkan lebih terpetakan. Hal ini juga memberikan peluang untuk memunculkan ide lain ditinjau dari segi bentuk yang akan diwujudkan.

\section{Perwujudaan}

Dalam proses perwujudan terdiri dari beberapa langkah yaitu Perwujudan karya berdasarkan sketsa, model, dan prototipe. Tahap ini merupakan tahap utama pembuatan karya seni. Dalam prosesnya berkaitan dengan penggunaan alat dan teknik, material, dan finishing. Proses dimana sampai menemukan kesempurnaan karya sesuai dengan desain dan ide yang diinginkan tahap dimana mewujudkan karya setelah melalui tahap eksplorasi dan perancangan agar mendapatkan karya yang dapat disajikan dengan sempurna. Evaluasi dan penilaian terhadap karya perlu dilakukan untuk menguji

\section{HASIL DAN PEMBAHASAN}

Tumbuhan dari sub-famili Rafflesiaceae dalam ilmu hayati merupakan tumbuhan holoparasites atau jenis tumbuhan 'parasit akar' yang dikenal dengan nama fotosintesis yaitu tumbuhan yang tidak dapat melakukan produksi makanan sendiri. Sebagaimana dalam (Lambers et al, 1998) holoparasites merupakan parasit (obligat) yang pemenuhan kebutuhan hidupnya bergantung sepenuhnya pada inang atau tumbuhan yang tempeli (di-rambati).

Bunga Rafflesia arnoldi sebagai tumbuhan endemik di Pulau Sumatra khusunya di Kota Bengkulu. Bunga Rafflesia arnoldii dikenal tidak memiliki daun sehingga tidak mampu melakukan fotosintesis sendiri, maka untuk memenuhi kebutuan hidupnya mengambil nutrisi dari pohon inangnya. Keunikan bunga Rafflesia arnoldii memiliki sifat-sifat biologi yang berbeda dengan tumbuhan lainnya yaitu memiliki daur hidup tahunan dan memparasiti spesies liana tertentu Diduga bahwa permasalahan lingkungan akan menjadi penyebab utama kepunahan Rafflesia arnoldii. Selain hal itu terjadinya kepunahan disebabkan oleh proses pertumbuhan kuncupkuncup bunga yang akan mekar dalam waktu singkat. Masa pertumbuhan bunga dapat memakan waktu sampai 9 bulan dan masa mekar hanya sekitar 5-7 hari, kemudian bunga Rafflesia arnoldii akan layu dan mati.

\section{Tinjauan tentang Seni serat}

Tinjauan seni serat (fiber art) sering diartikan dengan seni tekstil keduanya sama-sama mngandung pengertian karya seni rupa yang mengunakan matrial dasar serat sebagai media dalam berkarya. Menurut beberapa ahli dan dalam KBBI, Serat (fiber) adalah suatu matrial yang perbandinganya panjang dan lebarnya sangat besar serta molekul penyusunan lebih kearah panjang.

Serat terbagi menjadi dua jenis yaitu serat alami dan serat buatan, bahan-bahan pembuatan serat alami yaitu berasal dari sumber daya alam baik itu dari hewani dan matrial organik. kapuk, serabut kelapa, enceng gondok, juga agel adalah beberapa contoh serat alam yang berasal dari tumbuhan. Kapas (cotton), rayon, rami, Woll dan sutra adalah serat yang berasal dari hewan, sementara serat asbes merupakan contoh dari serat yang berasal dari serat sintetis adalah serat yang sengaja dibuat oleh manusia untuk memenuhi kebutuhan. Serat buatan terdiri dari 3 bagian yang berasal dari

Serat buatan dan telah mengalami proses polimerisasi lanjutan seperti Viskosa, Asetat, dan Kumproamonium. Ada juga yang berasal dari hasil sintetis polimerisasi misalnya, polyester, nylon, poliuretan, dan polivinil. Sedangkan serat dengan bahan dasar anorganik contohnya seperti serat logam dan gelas.

\section{PEMBAHASAN}

\section{Proses Penciptaan}

\section{Data acuan}

Data acuan merupakan komponen penting dalam peroses penciptaan karya seni meliputi data gambar maupun tulisan sangat membantu penulis untuk mengesplorasi dan menjadi batasan penulis untuk mengembangkan ide yang diangkat dalam penciptaan. Data-data yang dikumpulkan berupa data tertulis maupun data-data gambar yang berkaitan dengan bunga Rafflesia arnoldi dan karya seni serat.

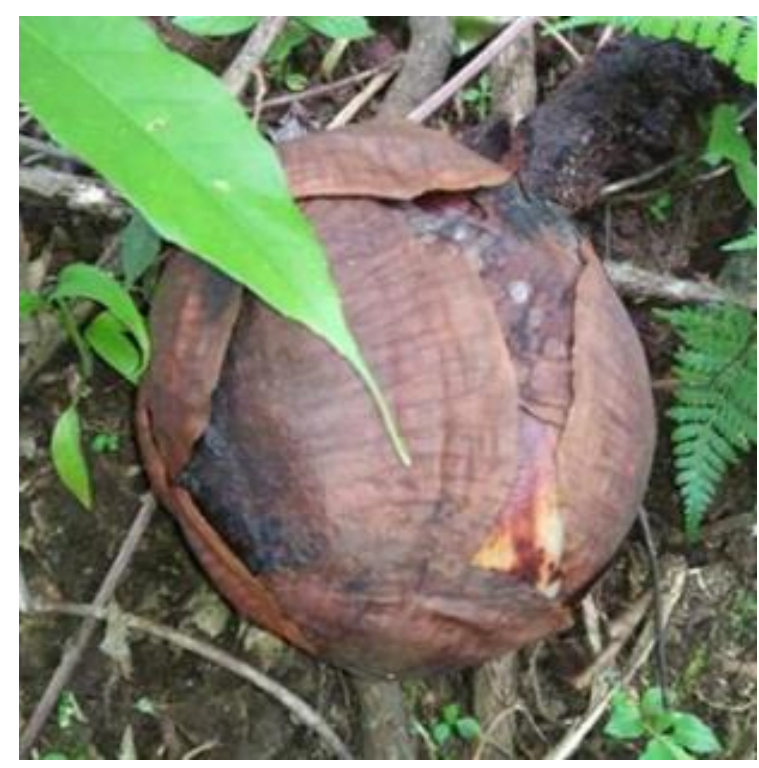

Gambar 1. Bongkol rafflesia arnoldi

Fotografer : Dio dian antoni w, 2019 


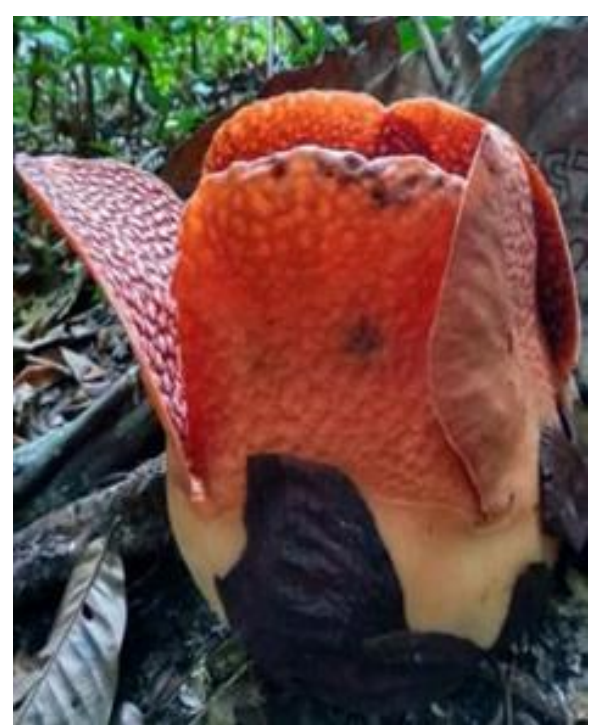

Gambar 2. kuncup bunga rafflesia arnoldi Fotografer: Dio dian antoni w, 2019

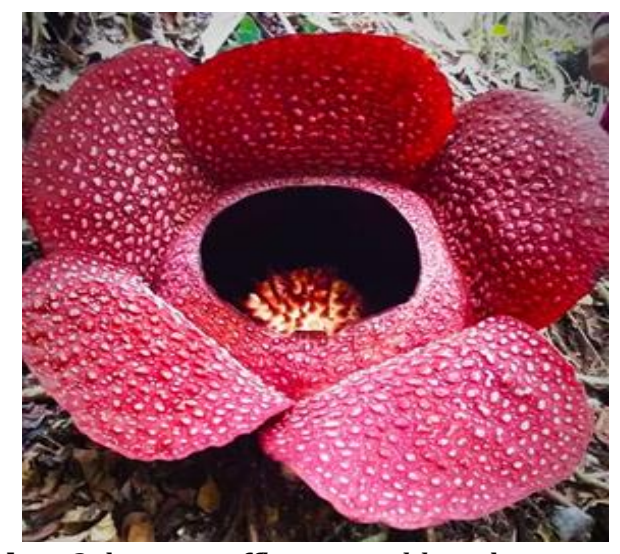

Gambar 3. bunga rafflesia arnoldi mekar sempurna Fotografer: Dio dian antoni w, 2019

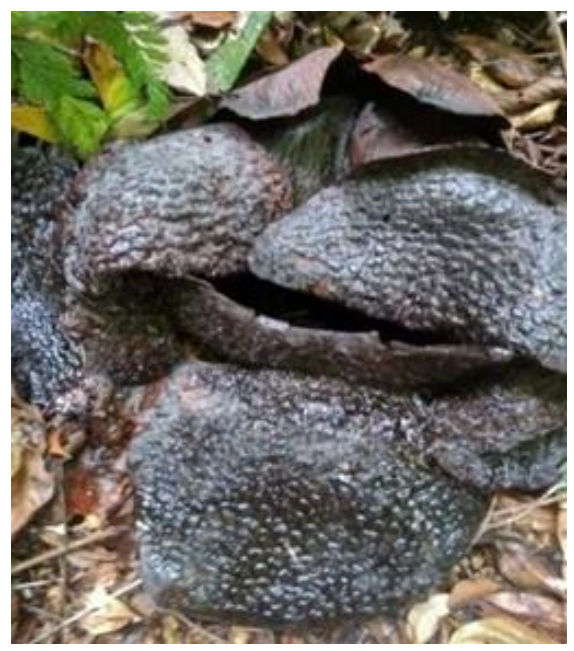

Gambar 4. bunga Rafflesia arnoldi telah layu dan mati

Fotografer: Dio dian antoni w, 2019

\section{Rancangan karya}

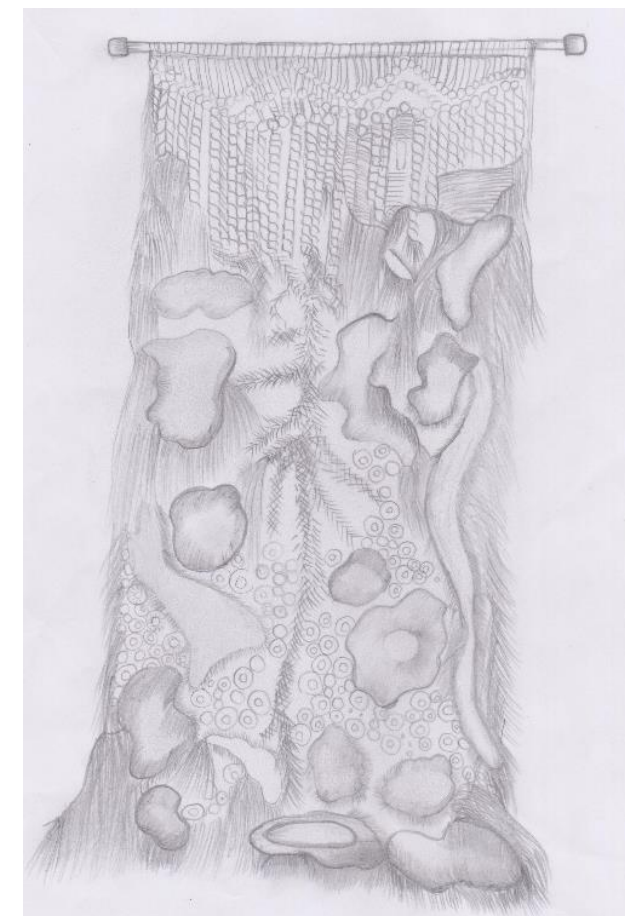

Gambar 5. Sketsa karya 1

Dokumentasi: Sehpenganti (2020)

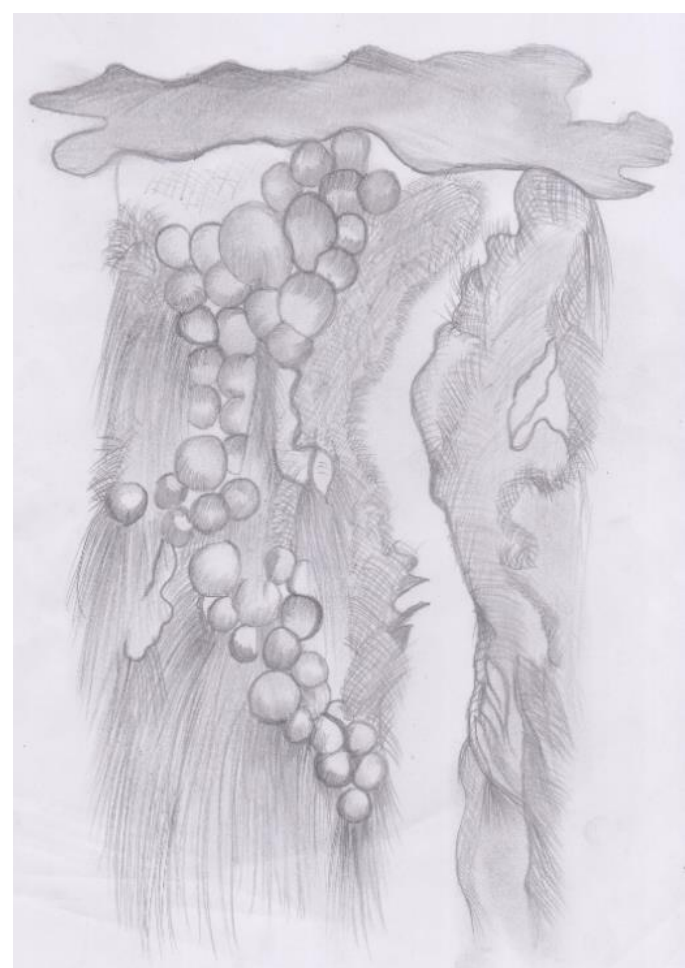

Gambar 6.Sketsa karya 2

Dokumentasi: Sehpenganti (2020) 


\section{Bahan dan teknik}

Kain goni yang dipilih penulis sudah mengalami proses pemintalan dan proses penenunan menjadi lembaran kain yang mengahasikan warna natural faktor lainnya kain goni dipilih karena memiliki kelebihan tersendiri yakni memiliki bahan yang ramah lingkungan, memiliki warna khas yakni coklat yang sangat mendukung kesan natural pada penciptaan karya penulis.

Pengunaan teknik dan bahan pendukung seperti benang serat alami dan serat buatan akan memberi tekstur dan kesan tersendiri pada karya yang akan diwujudkan. Teknik yang digunakan adalah teknik sulam, makram, jahit aplikasi, dan sentuhan akhir mengunakan payet. Bahan dan teknik yang digunakan adalah sebagai berikut:

\section{1) Bahan}

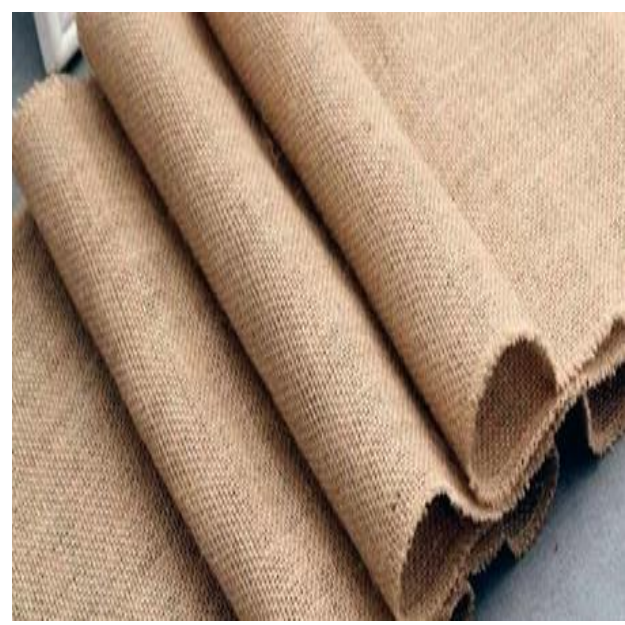

Gambar 7. kain goni

Dokumentasi : Sehpenganti (2020)

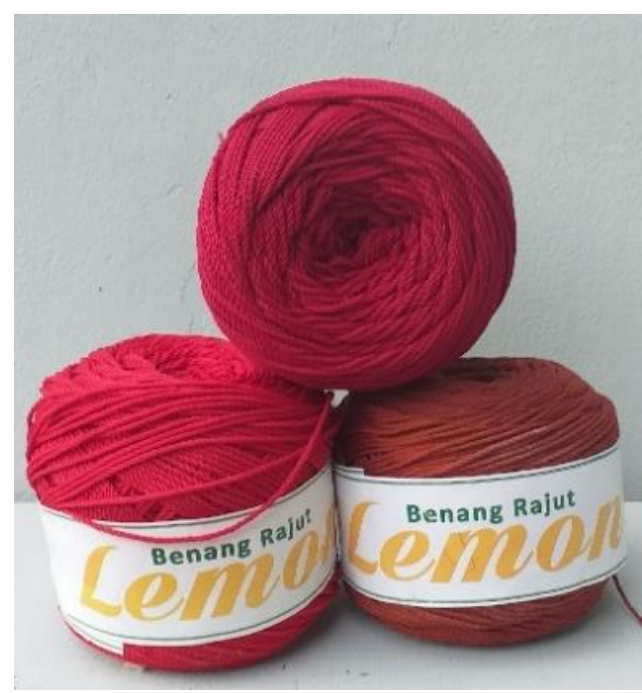

Gambar 8.benang rajut

Dokumentasi: Sehpenganti (2020)

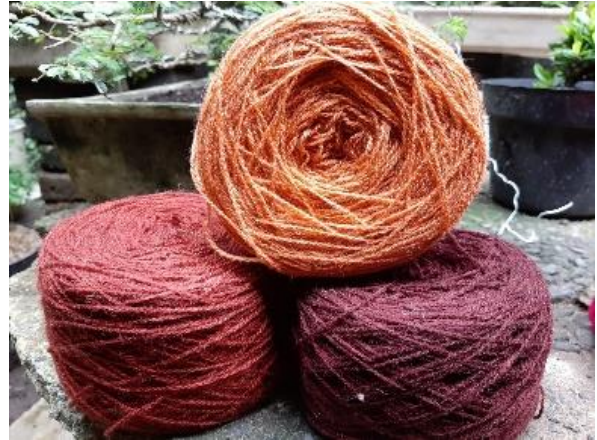

Gambar 9. benang woll

Dokumentasi: Sehpenganti (2020)

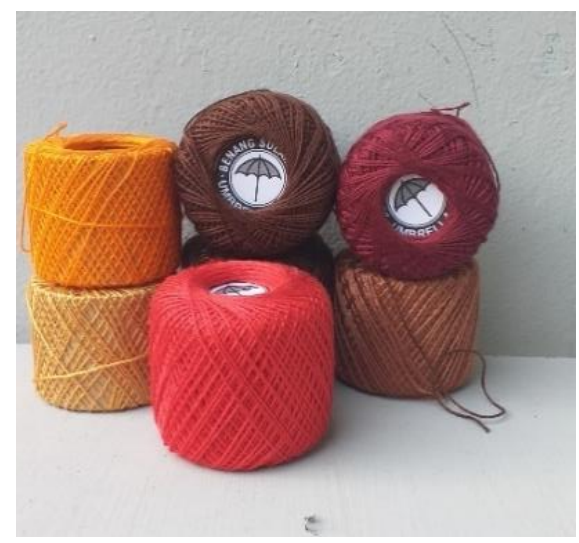

Gambar 10. benang sulam

Dokumentasi: Sehpenganti (2020)

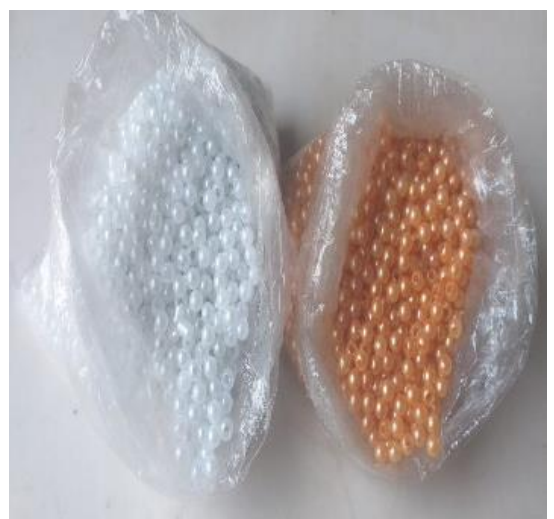

Gambar 11. Sketsa 3

Dokumentasi: Sehpenganti (2020)

\section{Tahap perwujudan}

a. Tahap pembuatan sketsa dan pola 1:1 pada kain goni lalu diteruskan ke proses pemotongann pola 1:1 untuk proses pembuatan pola kelopak bunga setelah selesai, proses pemolaan dilanjutkan dengan proses menjahit pola dan pengisian dakron agar membentuk kelopak dan bongkol.

b. Pemasangan aplikasi bentuk kelopak dan bongkol pada kain goni sesuai pola yang telah dibuat. 
c. Finising dengan memasang payet pada kelopak bunga. Pemasangan aplikasi makram dan sulaman.

\section{HASIL PENCIPTAAN KARYA}

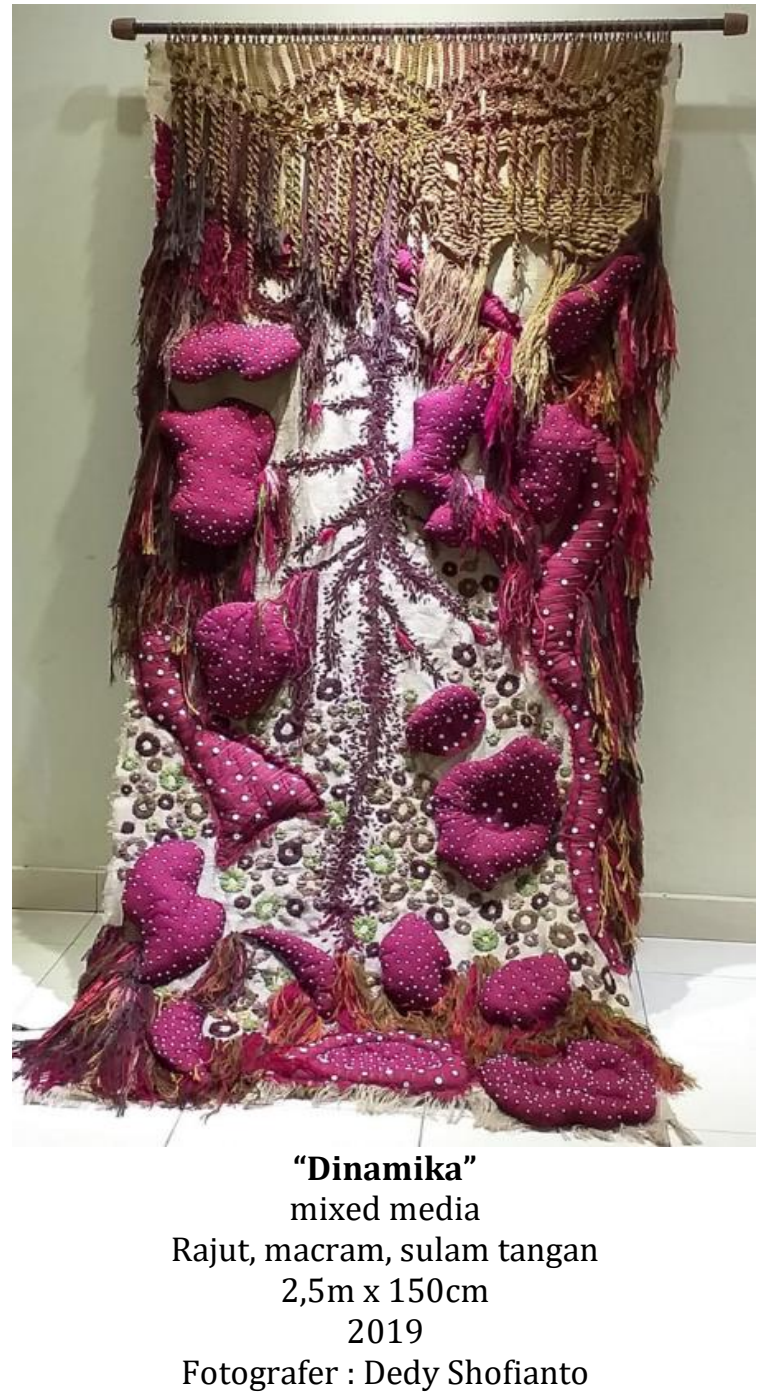

karya ini berjudul "Dinamika" karya ini sengaja membongkar bentuk struktur bentuk bagian bunga Rafflesia Arnoldi kedalam bentuk terpecah dan penempatan yang tidak teratur menjadi simbol kerusakan bunga rafflesia arnoldi pada habitat yang dilakukan oleh oknum-oknum tidak bertangung jawab. Bentuk struktur bunga rafflesia arnoldi yang menyerupai kelopak- kelopak bunga menjadi sebuah simbol penulis yang terpisah dengan keluarga dan belajar menyesuaikan pola hidup di perantauan. Bentuk-bentuk akar yang menjulur menjadi simbol penulis yang berusaha bertahan hidup seperti layaknya tumbuhan parasit yang terkadang hal itu bisa menguntungkan yang ditumpangin dan bisa saja hal itu menjadi merugikan yang ditumpangi selama bertahan hidup.

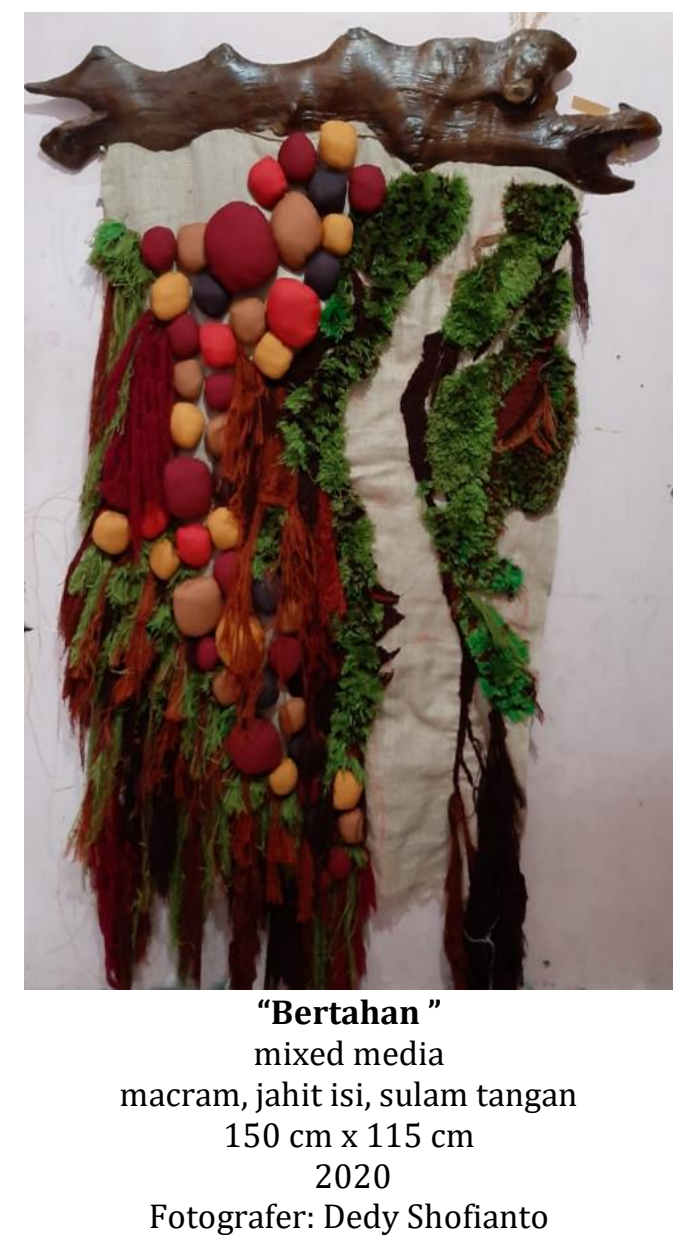

Karya yang berjudul “ Bertahan" merupakan visual dari bogkol bibit bunga Rafflesia. Bongkol atau bibit bunga rafflesia arnoldi yang yang belum mekar diibaratkan sebagai diri penulis dalam lingkungan keluarga yang memiliki banyak saudara dan memiliki pola berfikir yang berbeda juga cara bertahan hidup yang berbeda pula namun, tidak semua bibit bongkol akan tumbuh dan mekar sempurna pada habitatnya. Disini penulis mencoba Berusaha bertahan dan menjadi yang terbaik tanpa melupakan asal usul dan latar belakang kehidupan yang ada.

\section{KESIMPULAN}

Karya seni merupakan media untuk menuangkan ide, gagasan, imajinasi, dan ekspresi diri. Di dalam seni manusia mengekspresikan ideidenya, pengalaman keindahan atau pengalaman estetiknya (Soedarso, 2006:41). Berkarya seni bukan sekedar menciptakan karya, melainkan ada suatu tanggung jawab moral dengan kepuasan batin terhadap karya yang diciptakan.

Proses kreatif penciptaan karya dimulai dengan mengeksplorasi sumber ide, data acuan dan landasan teori. Selanjutnya melakukan tahapan eksperimen dengan mengolah material dengan 
teknik perwujudannya yaitu makram, kolose jahit isi bunga Rafflesia Arnoldi dan sulam tangan. Material utama yang digunakan terdiri dari kain goni dan kain asahi, juga pengunaan berbagai macam jenis benang dan serat alam serta payet. Dalam proses eksekusi, wujud karya yang dihasilkan berjumlah dua buah karya panel dua dimensi. Setiap karya-karya yang disajikan dari karya kolose jahit isi dan aplikasi macram dan sulam tangan yang memiliki bentuk, makna dan pesan yang berbeda-beda.

\section{DAFTAR PUSTAKA}

Anas, Biranul. (2006), Ikatan Silang Budaya Seni Serat, Bentara Budaya, Jakarta.

Azalea,dkk. (2014), Kreasi Rajut Paling Cute Spesial Bikin Perhiasan yang Nggak Pasaran, Media Pressindo, Yogyakarta.

Abdullah, Hamidin. (2010), Jurnal Perintis Pendidikan Fakulti Seni Lukis dan Seni Reka (UiTM), Editorial Journal INTI FSSR INTI Jilid 18 (Bil.1).

Budiman, Kris. (2011), "Semiotika Visual”, Konsep, Isu, dan Problem Ikonitas, Jalasutra, Yogyakarta.

Brower, M.A.W. (1998), Alam Manusia dalam Fenomenologi, PT Gramedia, Jakarta.

Budiyono, dkk. (2008), Kriya Tekstil untuk Sekolah Menengah Kejuruan Jilid 1, Direktorat
Pembinaan Sekolah Menengah Kejuruan Direktorat Jenderal Manajemen Pendidikan Dasar dan Menengah Departemen Pendidikan Nasional, Jakarta.

Djelantik. (2004), Estetika Sebuah Pengantar, Media Abadi, Yogyakarta.

Gie, The Liang. (2004), Filsafat Keindahan, Pusat Belajar Ilmu Berguna (PUBIB), yoyakarta.

Gustami, Sp. (20040), Proses Penciptaan Seni Kriya "Untaian Metodologis", Yogyakarta: Institut Seni Indonesia Yogyakarta

Hamy, Stephanus dan Debbie S.Suryawan. (2011), Sulam Tapis Lampung (Mengolah Wastra Indonesia), Jakarta: PT Gramedia Pustaka Utama.

Kartika, Dharsono Sony dan Nanang Ganda Perwira. (2004), Pengantar Estetika, Rekayasa Sains, Bandung.

Kartika, Dharsono Sony. (2017), Seni Rupa Modern, Rekayasa Sains, Bandung.

Langer, Suzanne K.(2006), Problematika Seni, Sunan Ambu Press, Bandung.

Malins, J. Ure J. And Gray C (1996), The Gap: Adressing Practice Based Research Training Requirements For Designers, The Robert University, Aberdeen, United Kingdom.

Saraswati. (1986), Seni Makrame III, Penerbit Bhratara, Jakarta.

Soedarso Sp. (2006), Trilogi Seni Penciptaan, Eksistensi, dan Kegunaan Seni. Institut Seni Indonesia Yogyakarta, Yogyakarta. 